\title{
The Reasons and Associated Injuries Related to Baby Walkers Use Among Children in Riyadh, Saudi Arabia
}

Yasir A. Albarrak ${ }^{1}$, Abdulrahman F. Algwaiz ${ }^{1}$, Abdulelah M. Sharaf ${ }^{1}$, Albaraa A. Alahmari ${ }^{1}$, Alwaleed K. Albadi ${ }^{1}$, Ahmed M. Almutairi ${ }^{2}$

1. College of Medicine, Imam Mohammad Ibn Saud Islamic University (IMSIU), Riyadh, SAU 2. Pediatrics, Imam Mohammad Ibn Saud Islamic University (IMSIU), Riyadh, SAU

Corresponding author: Abdulrahman F. Algwaiz, itsgweizer@gmail.com

Abstract
Background: Baby walkers (BW) are devices commonly used for helping babies' mobility. However, it is
associated with different types of injuries. Parents still use BWs and believe that it promotes early walking.

Objectives: This study aimed to estimate the use of baby walkers among children in Riyadh, Saudi Arabia, to identify the parental reasons for using BW, and to list their associated injuries.

Methods: This is a descriptive, cross-sectional study conducted between January 9, 2021, and January 31, 2021. A self-administered questionnaire was distributed through online means. We included all families living in Riyadh who have at least one child that is older than six months and younger than 36 months.

Results: This study included a total of 977 responders, of which, the majority 765 (78.3\%) were baby walker users and 212 (21.6\%) were non-users. Among those families using BW, the highest reason behind using them was to help the baby walk earlier (27.3\%). However, believing that there is no need for using BW is the highest reason in the non-user group (29.40\%). Fifteen percent of the responders reported that they had injuries related to BW usage and most of those injuries were falling downstairs (51.7\%). The level of awareness regarding the disadvantage of BW was high in BW non-users (21.1\%) compared to BW users (5.1\%).

Conclusion: The results of our study show that the prevalence of BW usage is high in Riyadh, Saudi Arabia. The majority of the families lack knowledge of the benefits and hazards of BW. Thus, pediatricians and the Ministry of Health have to increase the awareness of BW. Furthermore, the government should ban their importation and selling.

Categories: Family/General Practice, Pediatrics, Public Health

Keywords: baby walker, saudi arabia, injury, reasons, child safety

Review began 06/18/2021 Review ended 08/09/2021 Published 08/12/2021

\section{(c) Copyright 2021}

Albarrak et al. This is an open access article distributed under the terms of the Creative Commons Attribution License CC-BY 4.0., which permits unrestricted use, distribution, and reproduction in any medium, provided the original author and source are credited.

\section{Introduction}

Baby walkers (BW) are devices that have a seat supported by wheels that make babies who did not develop walking skills yet move around easily [1]. People have been using BW for their children since the early 1600 s [2]. It is noticeable that the use of BW is popular among families from different communities around the world as this was apparent by many studies that were done in the last 30 years, which showed usage rates between $47 \%$ and $83 \%$ in infants younger than 15 months of age [3-7]. High prevalence rates of BW use correlate with high sale rates which were shown by a study that was done in the United States demonstrated that the sales of BW exceeded 600,000 pieces per year in 2005 with an estimated benefit of about 100 million dollars annually [8]. Parents gave many reasons behind the use of baby walkers, such as keeping the baby entertained, aid in the development of walking skills, allow time to rest from supervising the child, and "keeping the baby safe" [6,9-11]. On the other hand, the evidence that exists nowadays states that the use of BW slows down the development of independent walking and increases the chance that the baby will get injured $[12,13]$. The number of injuries reported to the National Electronic Injury Surveillance System (NEISS) of the US Consumer Product Safety Commission (CPSC) was 20,100 and 8800 in 1995 and 1999, respectively. Because of the mandatory and voluntary standards that were set by the CPSC for BW factories, the number of injuries declined significantly [14]. Moreover, NEISS reported 230,676 cases of children younger than 15 months who were treated for baby walker-related injuries in emergency departments in the period from 1990 to 2014 [15]. The American Academy of Pediatrics suggests a banning of production and sale of moveable BWs [1]. On April 7, 2004, Canada implemented the ban on import and sales of BW [16]. A comparison between BW users and non-users showed no significant variance in accelerating the acquisition of the skill of walking independently [17,18]. Another study found that BW could cause a delay in the development of walking skills [12]. The previous literature that is mentioned earlier showed the high prevalence of BW users that reflected the increasing numbers of injuries, we found that there is a lack of 
studies investigating this aspect in Saudi Arabia. Furthermore, we hope that this study will help the authorities in Saudi Arabia such as the Ministry of Health in knowing and estimating the number of BWassociated injuries in order to increase the campaigns and education of the public about the harms of its usage. In addition to that, this research could help the Ministry of Commerce to force the importers of BWs to set safety requirements and warning labels. In this study, we aimed first to estimate the prevalence of using BW among children in Riyadh, Saudi Arabia, second to identify the parental reasons for using BW, third to assess the awareness level about dangers and disadvantages of using BW, fourth to compare the parental attitude of using a BW with other general practices related to child safety, and fifth to list the BW associated injuries and their outcomes.

\section{Materials And Methods}

This is a descriptive, cross-sectional study approved by Institutional Review Board, King Saud Medical City (H1RE-26-Nov20-02). The study was carried out among the general population in Riyadh, Saudi Arabia, in the period from January 9, 2021, to January 31, 2021.

Riyadh is the capital city of Saudi Arabia and is considered the largest city among Arabic Gulf countries with a population estimate of over eight million. We targeted all families who are living in Riyadh. Our Inclusion criteria included all families who have at least one child who is older than six months which is the expected age to BW and younger than 36 months to get better recalling information regarding the usage of BW. We excluded any respondents who are not a first-degree relative to the child. Our final concluded sample size was 977 participants. Due to the circumstances related to the coronavirus disease 2019 (COVID-19) pandemic and the associated commitment to social distancing in order to contain the spread of the disease, we found it difficult and unsafe to interview the participants face to face. To overcome this problem, we took an action to distribute the questionnaire through online means. Consent was taken from the respondents when they agreed to fill the online survey. The self-administered questionnaire was developed in English and translated into Arabic. This questionnaire was designed and written by an expert pediatric consultant and the content was reviewed by other two pediatric consultants. To further assure the reliability and comprehension of the survey, a pilot study was performed with a sample size of 35 respondents. The questionnaire is divided into five parts: (i) demographic data of the parents and the targeted child (e.g., gender, age, level of education of the parents, and relation to the child); (ii) reasons and thoughts behind using and non-using BW; (iii) assess the level of BW awareness among the respondents by the following method - any respondent who answer the following two questions "baby walkers promote early walking" and "baby walker is safe for babies" correct was considered aware and respondent who answers one of the questions incorrectly was considered unaware; (iv) injuries associated with BW use; (v) assessment of general practices regarding the targeted child's safety using eight questions - the questions were (1) have you ever used an infant car seat for this child (when he/she was an infant)? (2) Did you ever leave your child home without the supervision of an adult? (3) Did you or another adult ever share a bed with your child during sleeping? (When he/she was less than four months of age.) (4) Did you ever put any pillow in your child's sleeping area? (When he/she was less than four months of age.) (5) Did you ever leave your child alone in the bathtub? (When he/she was an infant) (6) Are medications secured in a safe place (out of child's reach) at home? (7) Is your child up to date on the recommended vaccines? (8) Does anyone smoke at the child's home? - the targeted child's safety score was as follows: optimal for those who answered eight questions correctly, good was seven to six, moderate was five to four, and poor was less than four. The gathered data were collected in a confidential manner to which only the research team will have access. Data were analyzed using SPSS version 23.0 (Chicago, IL: SPSS Inc.). The frequencies, percentages, mean, and standard deviation were conducted. Chi-square $\left(\chi^{2}\right)$ was used to test the differences between the nominal data. The independent t-test was used to assess the differences between BW users and non-users. A p-value less than 0.05 was considered statistically significant.

\section{Results}

A total of 977 people participated in the study including 765 BW users and 212 BW non-users, with the dominance of mothers' participation nearly $(\approx 60 \%)$ for both groups $(\mathrm{p}<0.05)$. For both groups, the majority of the mothers' and fathers' education levels were university/college with the BW users being higher $(p<0.05)$. Further details regarding socio-demographic information are in Table 1 . The participants were given a list of choices behind the specific reasons for using and not using BW. "To make the baby walk earlier" was the highest chosen reason behind using BW (27.3\%), followed by "to be used for the baby's entertainment" (20.8\%). "Received it as a present” was the least chosen reason behind using BW (3.7\%). Pointed that the top reasons behind not using BW were "it is unnecessary" (29.40\%), followed by "it is hazardous" (24.10\%). "It makes the baby get bored easily" was the least chosen reason given behind not using BW (2.8\%).

\begin{tabular}{|c|c|c|c|c|}
\hline \multicolumn{2}{|l|}{ Factor } & BW user (765) & BW non-user (212) & $x^{2} / t / p$ \\
\hline & \multirow{2}{*}{ Father } & 125 & 43 & \\
\hline & & $16.3 \%$ & $20.3 \%$ & \\
\hline
\end{tabular}




\section{Cureus}

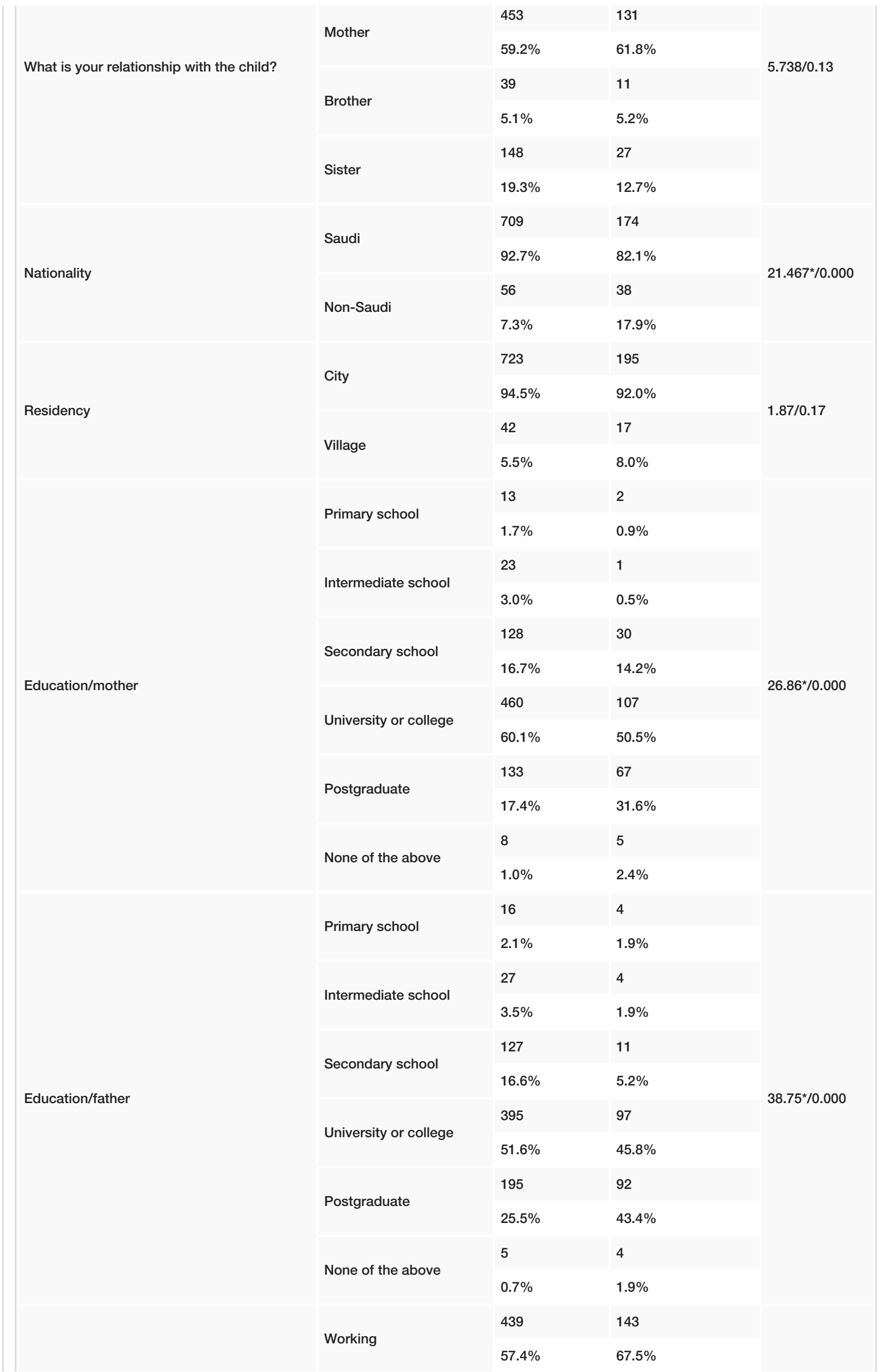




\section{Cureus}

\begin{tabular}{|c|c|c|c|c|}
\hline \multirow[t]{2}{*}{ Mother's occupation } & \multirow{2}{*}{ Not working } & 326 & 69 & \multirow[t]{2}{*}{$6.99 * / 0.000$} \\
\hline & & $42.6 \%$ & $32.5 \%$ & \\
\hline \multirow{4}{*}{ Child gender } & \multirow{2}{*}{ Male } & 423 & 128 & \multirow{4}{*}{$1.744 / 0.18$} \\
\hline & & $55.3 \%$ & $60.4 \%$ & \\
\hline & \multirow{2}{*}{ Female } & 342 & 84 & \\
\hline & & $44.7 \%$ & $39.6 \%$ & \\
\hline \multirow{4}{*}{ First child? } & \multirow{2}{*}{ Yes } & 228 & 122 & \multirow{4}{*}{$55.57^{\star} / 0.000$} \\
\hline & & $29.8 \%$ & $57.5 \%$ & \\
\hline & \multirow{2}{*}{ No } & 537 & 90 & \\
\hline & & $70.2 \%$ & $42.5 \%$ & \\
\hline \multirow{6}{*}{ How many other children do you have } & \multirow{2}{*}{ One child } & 71 & 23 & \multirow{6}{*}{$9.20 * / 0.000$} \\
\hline & & $13.2 \%$ & $25.6 \%$ & \\
\hline & & 154 & 22 & \\
\hline & I wo cminaren & $28.7 \%$ & $24.4 \%$ & \\
\hline & \multirow{2}{*}{ Three children or more } & 312 & 45 & \\
\hline & & $58.1 \%$ & $50.0 \%$ & \\
\hline \multicolumn{2}{|l|}{ Age of participant $(M e a n \pm S D)$} & $31.71 \pm 10.42$ & $29.50 \pm 9.77$ & $1.52 / 0.13$ \\
\hline \multicolumn{2}{|l|}{ Age of child in months (Mean $\pm S D)$} & $19.18 \pm 17.24$ & $19.08 \pm 17.28$ & $0.08 / 0.94$ \\
\hline
\end{tabular}

\section{TABLE 1: Socio-demographic information $(n=977)$}

${ }^{*} \mathrm{P}$-value $<0.05$

BW: baby walkers; $\mathrm{x}^{2} / \mathrm{t} / \mathrm{p}$ : chi-square/independent $\mathrm{t}-\mathrm{test} / \mathrm{p}$-value

Further details are in Table 2 and Figure 1. BW awareness was measured by two items (promotion of early walking and safeness), and the statements were classified into either "aware" or "unaware" participants for both groups. So, a chi-square test was conducted to test the level of awareness among BW users and nonusers, the results indicate that there was a significant difference between BW users and non-users $\left(\chi^{2}=54.95 / \mathrm{p}<0.05\right)$. Among all participants, a significant difference was found $\left(\chi^{2}=669.89 / \mathrm{p}<0.05\right)$. The overall level of awareness was low, $8.6 \%$ of the participants were classified as aware, while the majority were classified as unaware (91.4\%). A total of $21.1 \%$ of BW non-users were aware of the disadvantages of BW use as compared to $5.1 \%$ of BW users. 


\section{Cureus}



TABLE 2: Reasons behind BW user and BW non-user

BW: baby walkers 


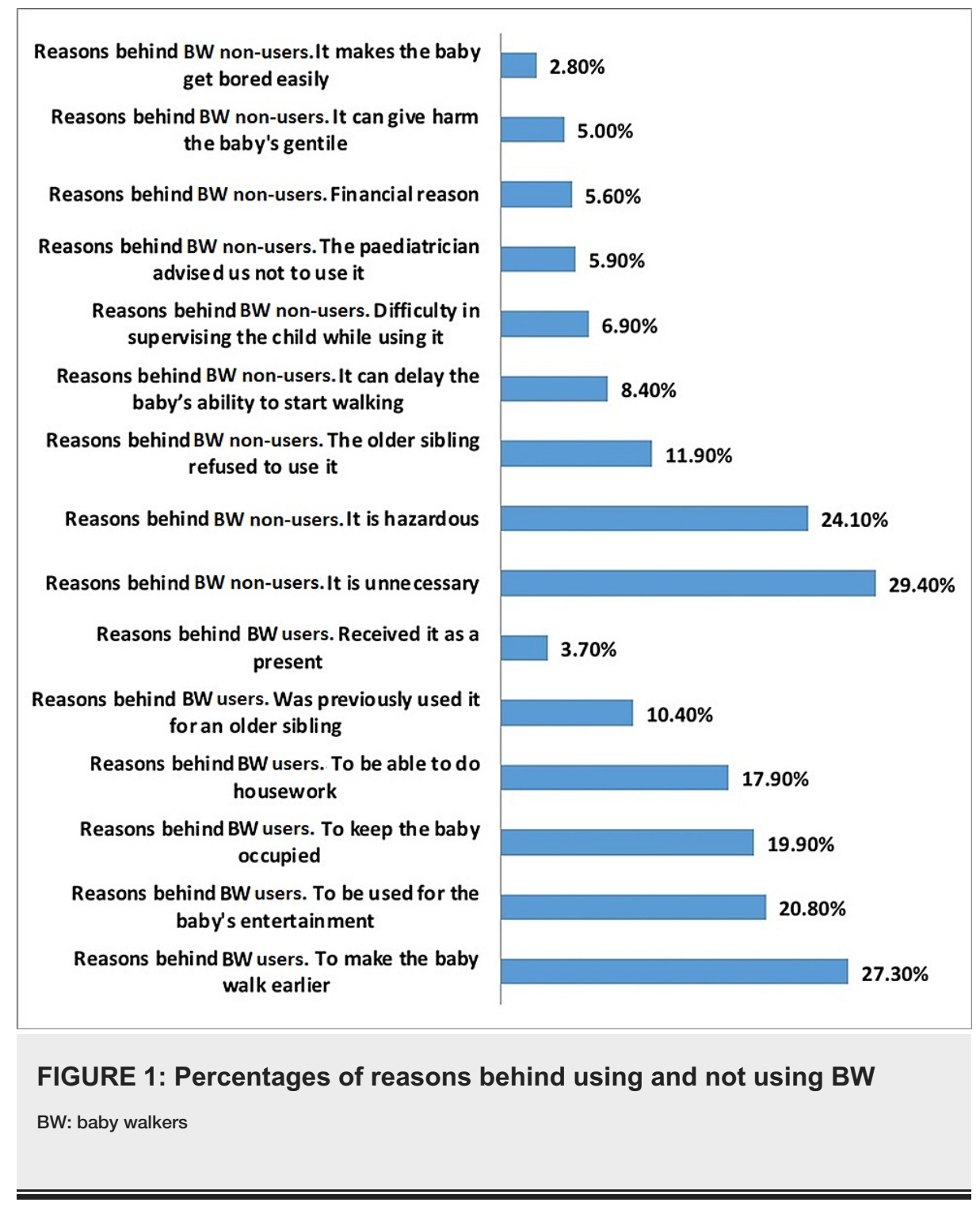

Tables 3, 4 show caregiver's attitude toward the child's safety was measured by eight items. The items were answered "true" and "false," so the possible score ranged between zero (the less relevant) and eight (the most relevant). The targeted child's safety score was as follows: optimal for those who answered eight questions correctly, good was seven to six, moderate was five to four, and poor was less than four. The results confirmed that the caregiver's attitude toward the child's safety was moderate with a mean score (5.87 \pm 1.34$)$, also there was an insignificant difference between users and non-user $(t=1.73, p>0.05)$. Also, a chi-square test was conducted to assess the level of practice in each statement, it confirmed that the correct answers were the domains $(\mathrm{p}<0.000)$. 


\section{Cureus}

\begin{tabular}{|c|c|c|c|c|c|c|c|c|}
\hline \multirow{2}{*}{ No. } & \multirow{2}{*}{ Statement } & \multirow{2}{*}{$\mathrm{N} / \%$} & \multicolumn{2}{|l|}{ All } & \multicolumn{2}{|c|}{ BW user } & \multicolumn{2}{|c|}{ BW non-user } \\
\hline & & & Aware & Unaware & Aware & Unaware & Aware & Unaware \\
\hline \multirow{2}{*}{1} & \multirow{2}{*}{ Baby walkers promote early walking } & $\mathrm{N}$ & 139 & 838 & 82 & 683 & 57 & 155 \\
\hline & & $\%$ & $14.2 \%$ & $85.8 \%$ & $10.7 \%$ & $89.3 \%$ & $26.9 \%$ & $73.1 \%$ \\
\hline \multirow{2}{*}{2} & \multirow{2}{*}{ Baby walker is safe for babies } & $\mathrm{N}$ & 308 & 669 & 208 & 557 & 100 & 112 \\
\hline & & $\%$ & $31.5 \%$ & $68.5 \%$ & $27.2 \%$ & $72.8 \%$ & $47.2 \%$ & $52.8 \%$ \\
\hline \multirow{3}{*}{\multicolumn{2}{|c|}{ Total awareness }} & $\mathrm{N}$ & 84 & 893 & 39 & 726 & 45 & 167 \\
\hline & & $\%$ & $8.6 \%$ & $91.4 \%$ & $5.1 \%$ & $94.9 \%$ & $21.2 \%$ & $78.8 \%$ \\
\hline & & \multicolumn{5}{|c|}{$x^{2}=669.89 * / 0.000$} & & \\
\hline
\end{tabular}

\section{TABLE 3: Level of awareness towards BW among BW user and BW non-user}

${ }^{*}$ P-value $<0.05$

BW: baby walkers; $x^{2}=$ Chi-square

\begin{tabular}{|c|c|c|c|c|c|c|}
\hline \multirow{2}{*}{ Level } & \multicolumn{2}{|l|}{ All } & \multicolumn{2}{|c|}{ BW user } & \multicolumn{2}{|c|}{ BW non-user } \\
\hline & $\mathrm{N}$ & $\%$ & $\mathrm{~N}$ & $\%$ & $\mathrm{~N}$ & $\%$ \\
\hline Optimal & 101 & $10.3 \%$ & 74 & $9.7 \%$ & 27 & $12.7 \%$ \\
\hline Good & 538 & $55.1 \%$ & 430 & $56.2 \%$ & 108 & $50.9 \%$ \\
\hline Moderate & 275 & $28.1 \%$ & 222 & $29.0 \%$ & 53 & $25.0 \%$ \\
\hline Poor & 63 & $6.4 \%$ & 39 & $5.1 \%$ & 24 & $11.3 \%$ \\
\hline
\end{tabular}

\section{TABLE 4: Caregiver's attitude toward the child's safety}

BW: baby walkers

Table 5 shows that $15 \%$ of the children have been exposed to BW-related injury. This section included children who were exposed to an injury-causing event. As presented in Table 5 and Figure 2, the top two chosen mechanisms of injury were "falling down the stairs" (51.7\%) and "flipping over a flat surface" (37.4\%). "Falling into the swimming pool" was the least selected mechanism (4.1\%). Table 5 and Figure 3 show the chosen outcomes of the children who were exposed to an injury. Most of them had no outcomes (42.9\%). Superficial hematoma or bleeding (35.4\%) was second. Drowning came last (0.7 \%). Further events and interventions of the children who were injured are shown in Table 5 and Figure 4 . The majority reported no further events and/or interventions were needed (42.2\%). Emergency visit (29.3\%) came second followed by bruising (13.6\%), while death came last $(0.7 \%)$.

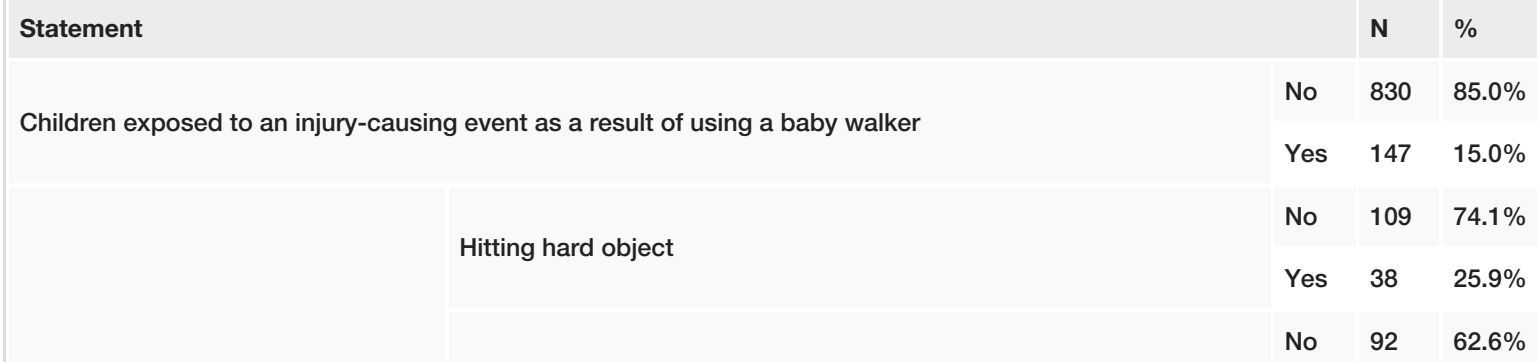

Flipping over a flat surface 


\section{Cureus}

\begin{tabular}{|c|c|c|c|c|}
\hline \multirow{7}{*}{ Falling into a swimming pool } & & Yes & 55 & $37.4 \%$ \\
\hline & \multirow{2}{*}{ Accessing dangerous items } & No & 136 & 92.55 \\
\hline & & Yes & 11 & $7.5 \%$ \\
\hline & \multirow{2}{*}{ Falling down the stairs } & No & 71 & $48.3 \%$ \\
\hline & & Yes & 76 & $51.7 \%$ \\
\hline & \multirow{2}{*}{ Falling into a swimming pool } & No & 141 & $95.9 \%$ \\
\hline & & Yes & 6 & $4.1 \%$ \\
\hline \multirow{16}{*}{ Outcome of the injury } & \multirow{2}{*}{ Fracture } & No & 124 & $84.4 \%$ \\
\hline & & Yes & 23 & $15.6 \%$ \\
\hline & \multirow{2}{*}{ Burns } & No & 144 & $98.0 \%$ \\
\hline & & Yes & 3 & $2.0 \%$ \\
\hline & \multirow{2}{*}{ Poisoning (ingestion of chemicals, drugs, foreign body) } & No & 145 & $98.6 \%$ \\
\hline & & Yes & 2 & $1.4 \%$ \\
\hline & \multirow{2}{*}{ Superficial hematoma or bleeding } & No & 95 & $64.6 \%$ \\
\hline & & Yes & 52 & $35.4 \%$ \\
\hline & \multirow{2}{*}{ Deep hematoma or bleeding } & No & 142 & $96.6 \%$ \\
\hline & & Yes & 5 & $3.4 \%$ \\
\hline & \multirow{2}{*}{ Head injury } & No & 133 & $90.5 \%$ \\
\hline & & Yes & 14 & $9.5 \%$ \\
\hline & \multirow{2}{*}{ Drowning } & No & 146 & $99.3 \%$ \\
\hline & & Yes & 1 & $0.7 \%$ \\
\hline & \multirow{2}{*}{ No outcome } & No & 84 & $57.1 \%$ \\
\hline & & Yes & 63 & $42.9 \%$ \\
\hline \multirow{12}{*}{ Further events intervention } & \multirow{2}{*}{ Emergency visit } & No & 104 & $70.7 \%$ \\
\hline & & Yes & 43 & $29.3 \%$ \\
\hline & \multirow{2}{*}{ Hospitalization in the ward } & No & 136 & $92.5 \%$ \\
\hline & & Yes & 11 & $7.5 \%$ \\
\hline & \multirow{2}{*}{ Long-term disability (describe further) } & No & 144 & $98.0 \%$ \\
\hline & & Yes & 3 & $2.0 \%$ \\
\hline & \multirow{2}{*}{ Death } & No & 146 & $99.3 \%$ \\
\hline & & Yes & 1 & $0.7 \%$ \\
\hline & \multirow{2}{*}{ Bruising } & No & 127 & $86.4 \%$ \\
\hline & & Yes & 20 & $13.6 \%$ \\
\hline & \multirow{2}{*}{ No further events and/or intervention } & No & 85 & $57.8 \%$ \\
\hline & & Yes & 62 & $42.2 \%$ \\
\hline
\end{tabular}

TABLE 5: Baby walkers associated injuries and outcomes 


\section{Cureus}

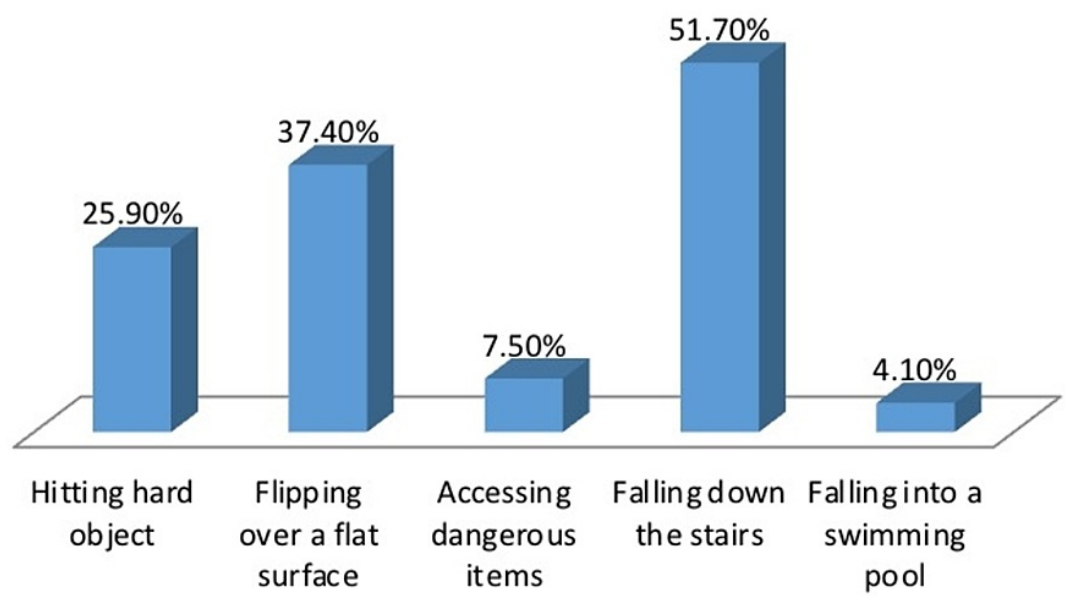

FIGURE 2: Mechanism of injury

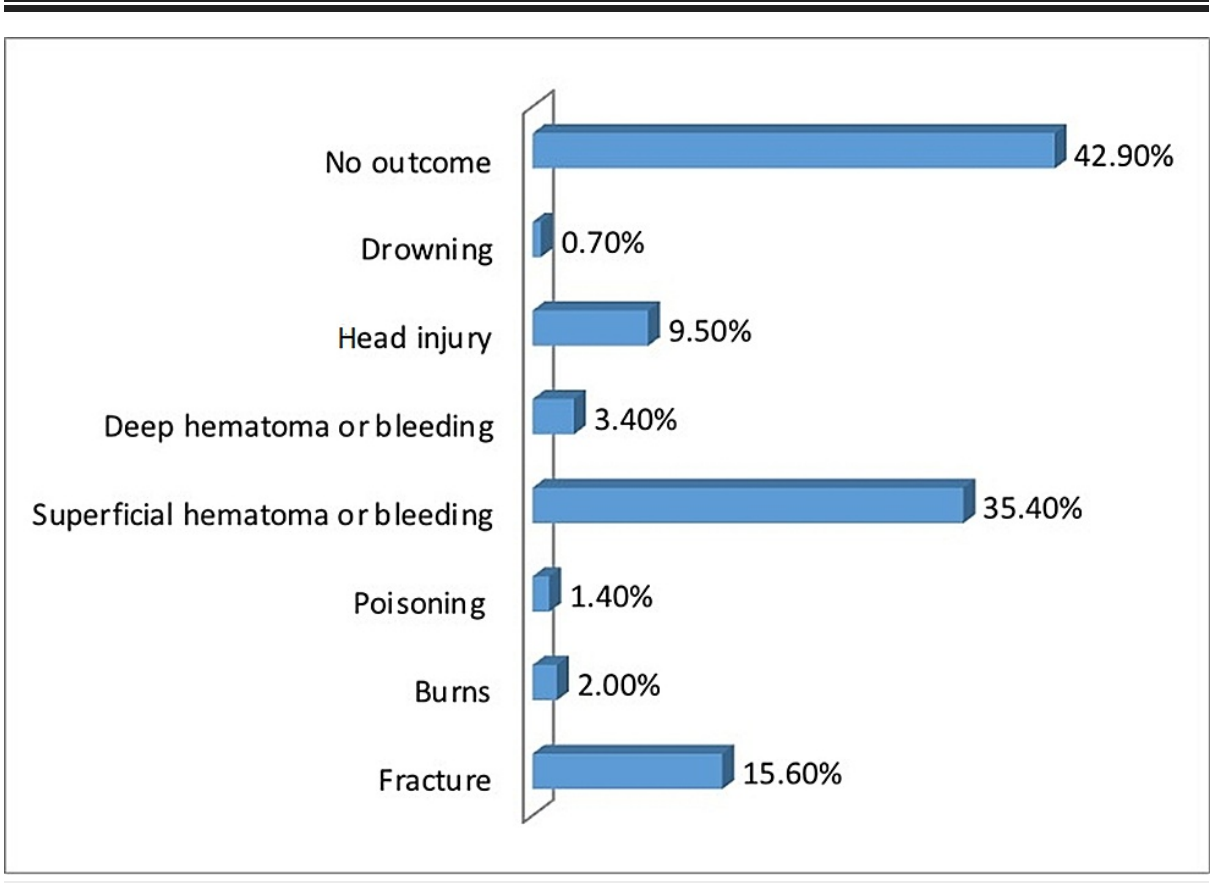

FIGURE 3: Outcomes of the injury 


\section{Cureus}

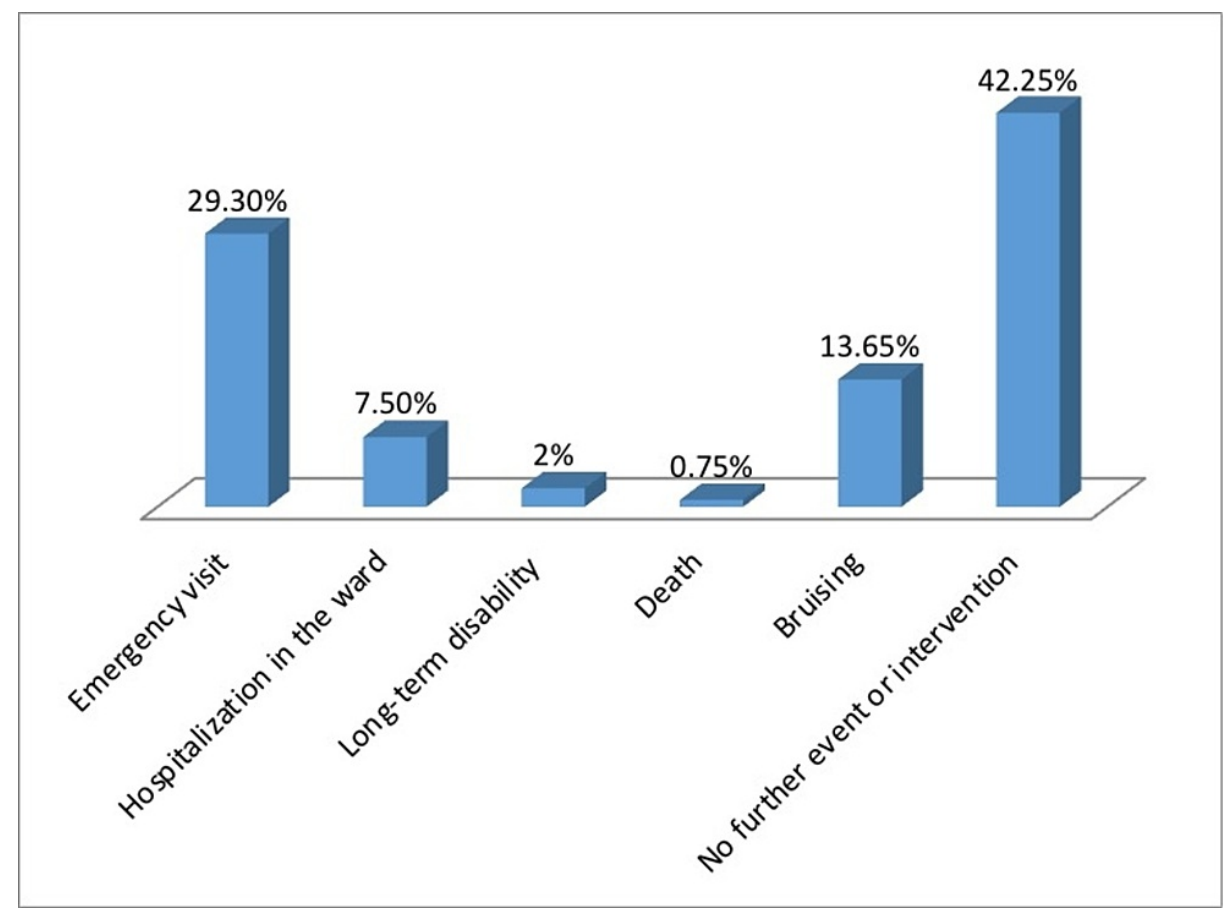

FIGURE 4: Further events or interventions

Table 6 and Figure 5 display the source of information regarding BW usage. A total of $39.1 \%$ had received their information from social media, followed by friends or relatives (non-health professional) (37.4\%); $29.8 \%$ had never received any information.

Source of information

My child's doctor

Friend or relative (non-health professional)

Friend or relative (health professional)

Written information (for example, books, leaflets, brochures, etc.)

Social media content and websites

Never received any information

\begin{tabular}{|c|c|c|}
\hline & $\mathbf{N}$ & $\%$ \\
\hline Yes & 208 & $27.2 \%$ \\
\hline No & 557 & $72.8 \%$ \\
\hline Yes & 286 & $37.4 \%$ \\
\hline No & 479 & $62.6 \%$ \\
\hline Yes & 135 & $17.6 \%$ \\
\hline No & 630 & $82.4 \%$ \\
\hline Yes & 227 & $29.7 \%$ \\
\hline No & 538 & $70.3 \%$ \\
\hline Yes & 299 & $39.1 \%$ \\
\hline No & 466 & $60.9 \%$ \\
\hline Yes & 228 & $29.8 \%$ \\
\hline No & 537 & $70.2 \%$ \\
\hline
\end{tabular}

TABLE 6: Source of caregivers' information 
Never received any information

Social media content and websites

Written information (for example: books, leaflets, brochures, etc)

Friend or relative (health professional)

Friend or relative (non-health professional)

My child's doctor

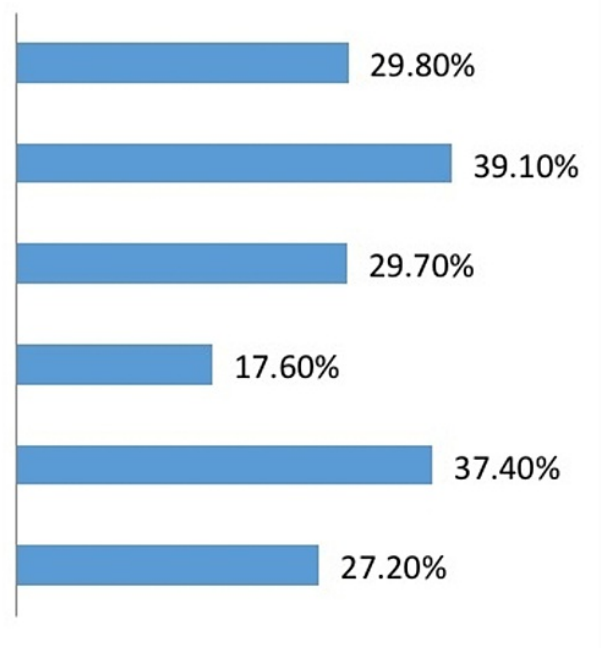

FIGURE 5: Source of caregivers' information

\section{Discussion}

Despite the lack of evidence that supports the benefits of BW usage and the earlier literature which showed the harms of BW and its associated injuries, we noticed that the number of BW users is still increasing and companies keep marketing BW as a product that helps the baby to walk. Unfortunately, no specific medical association in Saudi Arabia has warned against BW use or run a public campaign to educate parents about the potential harms of using BW. In the present study, we aimed to identify the prevalence of BW users, possible reasons for using BW, and the associated injuries of its use. Moreover, the levels of awareness and safety practices among BW users and non-users were measured.

The prevalence of BW users in our study (78\%) is similar to previous studies done in a high-income country like the United Arab Emirates and other middle-to-low regional countries that showed a prevalence rate between $54 \%$ and $87 \%$ [19-21]. Interestingly, most of BW non-users mothers (82.1\%) have either a bachelor's degree or postgraduate, while the percentage decreased in mothers of BW users to $77.5 \%$ with a significant $\mathrm{p}$-value of $<0.05$. A similar result identified in a previous study that was done in Turkey stated that lower maternal education was considered a factor for using BW [20]. Although the difference in the level of education between BW users and non-users is found statistically, we found that both users and non-users gave a satisfying level of education with the non-BW users having a slightly higher level of education. With regards to this, we think that the level of education should not be taken as a strong factor regarding the decision of using BW in our study.

From the late 1990s till we established our study, parents gave the same common reasons behind using BW. For example, most of the parents in our study and previous studies believe that BW promotes early waking and keeps the baby entertained and occupied $[6,19,20]$. Although there is no evidence yet to prove their reasons, the evidence has been found to be against their beliefs. A previous study mentioned that a baby's development can be negatively affected by BW [12]. On the other hand, BW non-users in our study and previous studies reported the same reasons behind not using BW. For example, they think it is unnecessary and it could be hazardous. Pediatricians play a major role in everything related to a baby's health; however, only $5 \%$ in our study and $7 \%$ in the previous study received advice from their pediatrician to not use BW [20].

Over the years, the issue behind the high numbers of BW users' misconceptions is that the parents believe BW promotes early waking and is generally safe. These two misconceptions were noticed in our study by measuring the level of awareness. Most of the participants (91.4\%) were unaware of the falsehood of these two misconceptions. Moreover, BW users were less aware compared to BW non-users. Similar results were noticed in an older study [4]. These two misconceptions are definitely wrong and the previous literature proved it [22].

In order to understand the general reason behind the huge prevalence of BW users, we investigated the other general safety practices towards the child. On one hand, the reason for this is to try to know if families who use BW have other unsafe general practices and it is expected for their use. On the other hand, to know the families that generally have safe practices and their decision to use BW was because of lack of knowledge about the harms of BW. Although there was no significant difference between BW users and non-users, we noticed more than half of BW users have good safety practices. This result can justify that the problem is related to the lack of knowledge and awareness regarding the use of BW. Conversely, an older study showed that BW users were more likely to have unsafe practices (e.g., leaving baby alone on high surface, using 
pillow in the baby's bed, and having a hot drink while holding the baby) [23].

As there are high numbers of BW users in our study, it was expected to see associated injuries among the users. Furthermore, we also asked BW non-users about previous injuries in any of their other children. In this study, 147 children (15\%) of both the BW user and older siblings of non-user group had been exposed to a previous injury in the past. Our results are considered high compared to $7.8 \%$ in Turkey and too low compared to $94 \%$ in Iraq $[7,20]$. The most common mechanism of injury in our study was falling down the stairs (51\%), which may explain the need for a mandatory safety standard like fall protection breaks. Similar result was noticed by data extracted from National Electronic Injury Surveillance System (NEISS) [15]. Although most of the injured children did not have an outcome to their injury and did not require any further intervention, $35 \%$ of them had superficial bleeding and $29 \%$ were taken to the emergency department. Similar results were noticed among 646 injuries in a study in the United Arab Emirates, emergency visits were 118 of these [21].

As for other self-reported surveys, our study has several limitations. First, there is a potential for recalling bias regarding the use of infant walkers. We tried to minimize it by shorting the recall periods, asking only about the recent use of walkers, and including the current infant and toddlers. However, in the final part of our study, we included information about other siblings and old injuries which could be recalled incorrectly and misestimated. Another limitation could be related to the selection technique of the sample. The majority of the involved caregivers in our report are moderately to highly educated, influencing the final assessment. Different results might be seen if the survey is conducted among other less-educated populations. However, the level of knowledge among them would be expected to be less than our assessment.

We think educating and raising the level of awareness among Saudi caregivers is an essential step in controlling similar harmful practices. It could be achieved directly by involving the health care providers and pediatricians who need to discuss such injury prevention topics during the routine well-baby visits, specifically at the four to six-month visits. Moreover, the Ministry of Health and the Saudi Pediatric Association should have a role in this issue by stating an announcement and spreading awareness to the community about the harms and the disadvantages of BW.

Higher steps need to be taken at the governmental level by forcing the importers of BW to put warning signs and make an effective system that protects the baby from associated injuries. And, if possible, holding the sales and importation of BW in Saudi Arabia by the Ministry of Commerce.

\section{Conclusions}

There is an obvious widespread use of BW in our result. Moreover, participants gave different reasons behind using BW as it is safe, enjoyable, and promotes early walking. These misconceptions should be corrected by pediatrics medical associations primarily and babies' physicians as they have a role in improving babies' health. The Saudi authorities like the Ministry of Health and Ministry of Commerce should take a serious step to educate people about the potential harms of BW as well as to limit its sales.

\section{Additional Information \\ Disclosures}

Human subjects: Consent was obtained or waived by all participants in this study. Institutional Review Board, King Saud Medical City issued approval H1RE-26-Nov20-02. Animal subjects: All authors have confirmed that this study did not involve animal subjects or tissue. Conflicts of interest: In compliance with the ICMJE uniform disclosure form, all authors declare the following: Payment/services info: All authors have declared that no financial support was received from any organization for the submitted work. Financial relationships: All authors have declared that they have no financial relationships at present or within the previous three years with any organizations that might have an interest in the submitted work. Other relationships: All authors have declared that there are no other relationships or activities that could appear to have influenced the submitted work.

\section{Acknowledgements}

The authors would like to thank Mosab Saad Alshamrani, Abdullah Zaki Alfahd, Meshari Nasser Alnazha, Mazen Saeed ALZahrani, Afnan Mohammed Almohandes, Amal Mishari Altamimi, May Saidan Saad Alharbi Taif Abdullah Alwadai, Lama Abdullah Al-khwildi, and Abdullah Mohammed Alojayr for helping in distributing the questionnaire.

\section{References}

1. American Academy of Pediatrics. Committee on Injury and Poison Prevention: Injuries associated with infant walkers. Pediatrics. 2001, 108:790-2. 10.1542/peds.108.3.790

2. Coats TJ, Allen M: Baby walker related injuries--a continuing problem . Arch Emerg Med. 1991, 8:52-5. 10.1136/emj.8.1.52

3. Mayr J, Gaisl M, Purtscher K, Noeres H, Schimpl G, Fasching G: Baby walkers -an underestimated hazard for 
our children?. Eur J Pediatr. 1994, 153:531-4. 10.1007/BF01957011

4. Laffoy M, Fitzpatrick P, Jordan M, Dowdall D: Attitudes to and use of baby walkers in Dublin . Inj Prev. 1995, 1:109-11. 10.1136/ip.1.2.109

5. Santos Serrano L, Paricio Talayero JM, Salom Pérez A, et al.: Patterns of use, popular beliefs and proneness to accidents of a baby walker (go-cart). Bases for a health information campaign. [Article in Spanish]. An Esp Pediatr. 1996, 44:337-40.

6. Bar-on ME, Boyle RM, Endriss EK: Parental decisions to use infant walkers. Inj Prev. 1998, 4:299-301. 10.1136/ip.4.4.299

7. Al-Nouri L, Al-Isami S: Baby walker injuries. Ann Trop Paediatr. 2006, 26:67-71. 10.1179/146532806X90637

8. Rodgers GB, Leland EW: A retrospective benefit-cost analysis of the 1997 stair-fall requirements for baby walkers. Accid Anal Prev. 2008, 40:61-8. 10.1016/j.aap.2007.04.003

9. Hapgood R, Woods A, Dyas J, Bentley E, Kendrick D: Baby walker safety - baby's minder or parent's problem? A qualitative analysis of clients' knowledge, attitudes and practices regarding baby walker use. Health Educ J. 2003, 62:350-8. 10.1177/001789690306200407

10. DiLillo D, Damashek A, Peterson L: Maternal use of baby walkers with young children: recent trends and possible alternatives. Inj Prev. 2001, 7:223-7. 10.1136/ip.7.3.223

11. Woods A, Hapgood R, Bentley E, Kendrick D, Dyas J: Talking about baby walkers: Insights about health education from the field. Health Educ J. 2003, 62:41-9. 10.1177/001789690306200105

12. Garrett M, McElroy AM, Staines A: Locomotor milestones and babywalkers: cross sectional study. BMJ. 2002, 324:1494. 10.1136/bmj.324.7352.1494

13. Thein MM, Lee J, Tay V, Ling SL: Infant walker use, injuries, and motor development. Inj Prev. 1997, 3:63-6. 10.1136/ip.3.1.63

14. Nursery products report. (2000). https://www.cpsc.gov/s3fs-public/pdfs/nursry00.pdf.

15. Sims A, Chounthirath T, Yang J, Hodges NL, Smith GA: Infant walker-related injuries in the United States . Pediatrics. 2018, 142:10.1542/peds.2017-4332

16. Information for Canadians travelling outside of Canada. (2020). https://www.canada.ca/en/healthcanada/services/consumer-product-safety/advisories-warnings-recalls/information-canad....

17. Crouchman M: The effects of babywalkers on early locomotor development . Dev Med Child Neurol. 1986, 28:757-61. 10.1111/j.1469-8749.1986.tb03929.x

18. Kauffman IB, Ridenour M: Influence of an infant walker on onset and quality of walking pattern of locomotion:an electromyographic investigation. Percept Mot Skills. 1977, 45:1323-9. 10.2466/pms.1977.45.3f.1323

19. Shiva F, Ghotbi F, Yavari SF: The use of baby walkers in Iranian infants . Singapore Med J. 2010, 51:645-9.

20. Dogan DG, Bilici M, Yilmaz AE, Catal F, Keles N: Baby walkers: a perspective from Turkey . Acta Paediatr. 2009, 98:1656-60. 10.1111/j.1651-2227.2009.01397.x

21. Barss P, Grivna M, Al-Hanaee A, Al-Dhahab A, Al-Kaabi F, Al-Muhairi S: Baby walker injury, disability, and death in a high-income middle eastern country, as reported by siblings. Inj Epidemiol. 2016, 3:17. 10.1186/s40621-016-0082-7

22. Taylor B: Babywalkers. BMJ. 2002, 325:612. 10.1136/bmj.325.7365.612

23. Kendrick D, Marsh P: Babywalkers: prevalence of use and relationship with other safety practices . Inj Prev. 1998, 4:295-8. 10.1136/ip.4.4.295 